
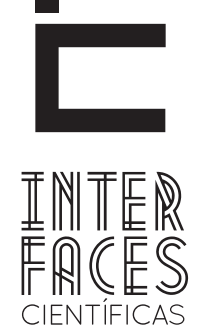

DIREITO

\title{
O MEIO AMBIENTE ENQUANTO DIREITO HUMANO FRENTE AOS PRINCÍPIOS DE DIREITO INTERNACIONAL E A QUESTÃO DA SOBERANIA DOS ESTADOS
}

Lucas Azevedo de Lima ${ }^{1}$

\section{RESUMO}

O presente trabalho procura fazer uma análise sobre o enquadramento do Meio Ambiente ecologicamente equilibrado, no rol dos Direitos Humanos. Como os direitos humanos transcendem a órbita Estatal e se constituem como instrumento de proteção da comunidade internacional, a questão ambiental adota uma dimensão supraestatal. Nesse ínterim, o objetivo do artigo é analisar os princípios de Direito Internacional à luz do meio ambiente, enquanto direito humano, que por se tratar de um Direito Universal de gestão compartilhada por todos os atores internacionais, acaba por se chocar contra a Soberania dos Estados,
Steffano Alves de Mingo $^{2}$

principalmente em relação à normativa e gestão das políticas ambientais. Noutro plano, busca-se demonstrar o fenômeno da internalização dos Tratados Internacionais de Direitos Humanos no ordenamento jurídico brasileiro.

\section{PALAVRAS-CHAVES}

Direito Ambiental. Direitos Humanos. Direito Internacional. Soberania Estatal. Direito Universal. Hierarquia Normativa. Supralegalidade. 


\section{ABSTRACT}

This paper attempts to make an analysis on the framework of ecologically balanced environment in the role of Human Right. As human rights transcend the orbit State and constitute an instrument of protection of the international community, the environmental issue adopts a supranational dimension. The aim of this paper is to analyze the principles of International Law under the perspective of the environment as a human right which as being a Universal Law of shared management tends to crash into the Sovereignty of States, especially regarding the rules and management of environmental politics. We also demonstrate the internalization phenomenon of international human rights in Brazilian legal system.

\section{KEYWORDS}

Environmental Law. Human Rights. International Law. State Sovereignty. Universal Law. Normative Hierarchy. Supra-legal.

\section{INTRODUÇ̄̃O}

Cada vez mais evidente é a preocupação do mundo com os problemas ambientais que vem causando degradação ambiental e asseverando a qualidade de vida dos seres vivos.

0 reconhecimento do meio ambiente ecologicamente equilibrado, enquanto direito humano, se deu num processo de construção histórica permanente, que remete a períodos longínquos.

A Declaração Universal dos Direitos Humanos, que se deu em 1948, implicitamente já derivava o

\section{RESUMEN}

En este trabajo se trata de hacer un análisis sobre el marco del medio ambiente ecológicamente equilibrado em el tema de los Derechos Humanos. Dado que los derechos humanos trascienden la órbita del Estado y constituyen como un instrumento de protección de la comunidad internacional, el tema ambiental adopta una dimensión supraestatal. De esta manera, el artículo tiene como objetivo analizar los principios del derecho internacional, a la luz del medio ambiente como un derecho humano, que por ser un Derecho Universal de gestión compartida por todos los actores internacionales, termina por opornerse a la soberanía de los Estados, especialmente en relación con las normas y la gestión de las políticas ambientales. En otro nivel, se busca demostrar el fenómeno de la internalización de los tratados internacionales de derechos humanos en el marco jurídico brasileño.

\section{PALABRAS CLAVE}

Derecho Ambiental. Derechos humanos. Derecho internacional. Soberanía del Estado. Derecho universal. Jerarquía normativa. Supralegalidad.

direito ao meio ambiente ecologicamente equilibrado. Não é só ela, destacam-se inúmeros outros instrumentos internacionais que adotavam postura no mesmo sentido, assim se deu em inúmeras resoluções adotadas pela Comissão de Direitos Humanos das Nações Unidas; pela ênfase dada pela Assembléia-Geral das Nações Unidas acerca da conexão entre a proteção ambiental e a realização dos direitos humanos; o reconhecimento do direito ao meio ambiente esculpido em dezenas de Constituições nacionais; entre outros. 
Percebe-se, até então, iniciativas de Organismos Internacionais e dos próprios Estados, no sentido de tratar o meio ambiente de modo especial, pela sua óbvia importância. Todavia, não se verifica uma ação conjunta e ordenada por parte dos estados na busca da proteção efetiva ao meio ambiente ecologicamente equilibrado, e o seu reconhecimento enquanto direito humano.

É nesse contexto que surge a Conferência de Estocolmo, que foi realizada entre os dias 5 e 16 de Junho de 1972, e contou com a participação de 113 países, 19 órgãos intergovernamentais, e cerca de 400 outras organizações intergovernamentais e não governamentais, e resultou na elaboração de um plano de ação contendo 109 recomendações, em forma de resolução, visando à proteção ambiental.

\section{AS NORMAS AMBIENTAIS COMO NORMAS DE DIREITOS HUMANOS}

As normas de Direito Humanos são criadas a partir de um amadurecimento gradual da comunidade internacional.

Esse amadurecimento surge após a segunda guerra mundial, sendo anseio da sociedade a reestruturação de um novo modelo de Direito Internacional Público, buscando a criação de mecanismos legais de proteção aos direito da pessoa humana contra arbitrariedades dos Estados e dos indivíduos que agem em seu nome.

Os Direitos Humanos, em contexto global, se deu com a formação do sistema de direitos humanos das Nações Unidas, com a criação da Declaração Universal dos Direitos Humanos de 1948. Após este marco houve a disseminação desta tendência de criação de proteção nos Estados e nas diversas regiões do plane-
A Declaração de Estocolmo merece destaque, uma vez que é tida como o marco inicial do Direito Internacional Ambiental. Abriu caminho para que as Constituições supervenientes reconhecessem o meio ambiente ecologicamente equilibrado, como um direito humano fundamental entre os direitos sociais do homem, com sua característica de direitos a serem realizados e direitos a não serem perturbado

A partir daí, a questão ambiental passou a ter uma dimensão e uma visibilidade maior, eis que centenas de países subscreveram a referida Declaração, sendo a temática ambiental tomada sob um viés da responsabilidade compartilhada de toda comunidade Internacional.

ta. Na região da interamericana, que gerência a proteção dos direitos humanos nos Estados-Membros da Organização dos Estados Americanos ou a assinatura do Pacto de São José da Costa Rica, ou também a Convenção Americana sobre Direitos Humanos.

Os Direitos Humanos tem o condão de proteger e promover a dignidade da pessoa humana e dentro destes anseios que o Direito ao meio ambiente foi classificado como direito de $3^{a}$ geração.

0 meio ambiente enquanto direito humano possui características marcantes. 0 meio ambiente, ecologicamente equilibrado, é de caráter difuso. Nas palavras de Uadi Lammêgo Bulos (2001, p. 1262):

Bem jurídico próprio, diferente daquele ligado ao direito de propriedade - porque ele não se funda num vínculo jurídico determinado, específico, mas em da- 
dos genéricos, contingentes, acidentais e modificáveis, motivo pelo qual não instrumentaliza um direito subjetivo típico, divisível, particularizável, que alguém possa usufruir individualmente; ao invés, o constituinte assegurou um direito exigível a quem incumba o dever jurídico de prestá-lo: o Poder Público.

Os eventuais danos causados ao meio ambiente afetam um número indeterminado de pessoas, por isso o aspecto difuso de sua tutela.

Neste sentido, a piora na qualidade de vida gerada pela degradação ambiental reflete nas condições de vida das pessoas, ou seja, indo de contrapartida ao princípio da dignidade da pessoa humana.

Assim, destacam-se também os ensinamentos de Cristiane Derani (2008, p. 245):

Não é possível, em nome deste direito ao meio ambiente, apropriar-se individualmente de parcelas do meio ambiente para o consumo privado. 0 caráter jurídico do meio ambiente ecologicamente equilibrado é de um bem de uso comum do povo. Assim, a realização individual deste direito fundamental está intrinsecamente ligada à sua realização social.

Ademais, por se tratar de um direito de $3^{a}$ geração, a preservação do meio ambiente é imprescindível, eis que a própria existência humana está condicionada à sua efetivação. Nesse contexto, a proteção ao meio ambiente ecologicamente equilibrado deve ser irrestrita, integral, e em todas as suas vertentes.

Visando à satisfação dessa proteção integral, é que o ordenamento jurídico Brasileiro adotou a Responsabilidade Objetiva por Dano Ambiental, além de aplicar a teoria do risco integral, modalidade extremada de punição a ser aplicada quando verificada a ocorrência de dano ambiental.

Nas palavras de Edis Milaré (2009, p. 66):

Em outras palavras, com a teoria do risco integral ambiental o poluidor, na perspectiva de uma sociedade solidarista, contribui - nem sempre de maneira voluntária - com a reparação do dano ambiental, mesmo quando presente o caso fortuito, a força maior ou o fato de terceiro. É o poluidor assumindo todo o risco que sua atividade acarreta: o simples fato de existir a atividade somado à existência do nexo causal entre essa atividade e o dano produz o dever de reparar.

Aqueles que se beneficiam da degradação ambiental provocada por terceiros e que de algum modo contribuíram, viabilizaram ou facilitaram a ocorrência do dano, ou do risco de dano, são considerados poluidores indiretos e devem ser responsabilizados por sua conivência com os atos do poluidor direto.

Essa ideia de proteção integral do meio ambiente e titularidade coletiva do bem ambiental foi devidamente inserida no princípio $n^{0} 21$ da Declaração de Estocolmo, e também no princípio de $n^{0} 2$ da Declaração do Rio, que respectivamente, assim dispõe:

PRINCÍPIO No 21 DA DECLARAÇÃO DE ESTOCOLMO: Conforme a Carta das Nações Unidas e os princípios de Direito Internacional, os Estados têm o direito soberano de explorar seus próprios recursos segundo sua política ambiental e têm o dever de agir de tal modo que as atividades exercidas nos limites da sua jurisdição ou sob seu controle não causem prejuízo ao meio ambiente de outros Estados ou nas regiões que não dependam de qualquer jurisdição nacional.

PRINCÍPIO No 2 DA DECLARAÇÃO DO RIO: Os Estados, de acordo com a Carta das Nações Unidas e com os Princípios do Direito Internacional, têm o direito soberano de explorar seus próprios recursos segundo suas próprias políticas de meio ambiente e de desenvolvimento, e a responsabilidade de assegurar que atividades sob sua jurisdição ou seu controle não causem danos ao meio ambiente de outros Estados ou de áreas além dos limites da jurisdição nacional.

Portanto, resta claro que o meio ambiente ecologicamente equilibrado deve ser analisado numa órbita de solidariedade e fraternidade, eis que a proteção ao meio ambiente constitui um poder-dever de todos os indivíduos, é a participação comunitária na preservação dos bens que são de interesse de todos. 


\section{SOBERANIA DOS ESTADOS - CONFLITO ENTRE OS PRINCÍPIOS DE DIREITO INTERNACIONAL}

Nessa seara, surge o princípio da Cooperação. Os Estados, atores internacionais, são detentores de uma responsabilidade conjunta e solidária pela preservação ambiental, de modo que se torna imprescindível uma atuação coordenada e não isolada, onde a convergência proporcione ações conjuntas com a finalidade de preservação ao meio ambiente.

O Direito Internacional na atualidade passou a incluir a regulamentação da cooperação internacional, preocupando com o modo em que os Estados, organizações internacionais e outros atores deverão proceder para alcançar os objetivos comuns globais, como a proteção do meio ambiente.

Por cooperação deve-se entender a atividade conjunta e solidária de diversos Estados em prol da preservação do meio ambiente, o que implica a interferência de parte da soberania de cada um, buscando o combate eficaz aos efeitos devastadores de atividades nocivas.

Inclusive para Kelsen acima da Constituição dos Estados haveria o fundamento do direito internacional, como norma hipotética fundamental, da qual decorrem todas as demais, inclusive as do Direito interno, até porque não haveria diferenças entre as normas internacionais e as internas.

Quando um Estado celebra um tratado ou se submete à competência de determinado Tribunal Internacional, o mesmo está aceitando a relativização de sua soberania e restringindo sua capacidade de deliberar sobre todos os assuntos de seu interesse.

A Cooperação Internacional deve-se entender a atividade conjunta e solidária de diversos Estados, não apenas no combate de problemas, mas sim em prol da preservação do meio ambiente, o que implica a interferência de parte da soberania de cada um buscando o combate eficaz aos efeitos devastadores de atividades nocivas.

Edis Milaré (2011, p. 1552), assim assevera:

A cooperação internacional em matéria ambiental, nada mais é que o reflexo vivo do reconhecimento da dimensão transfronteiriça e global das atividades degradadoras exercidas no âmbito das jurisdições nacionais, cujas seqüelas podem alcançar muito além do previsto. Isso significa que o princípio da cooperação internacional reflete as tendências ditadas pelo conjunto da ordem internacional contemporânea, dada a interdependência crescente entre as nações, à procura de um equacionamento e da solução de problemas que transcendem as fronteiras nacionais e a geopolítca tradicional.

Ainda na lição de Marcelo D. Varella (2010, p. 7):

O princípio da cooperação internacional significa que os Estados devem agir em conjunto, colaborando para a busca de objetivos comuns. Justifica a ação em harmonia de forma a evitar e buscar soluções compartilhadas para os problemas.

Nosso Estatuto Supremo, em seu art. $4^{\circ}$, IX, estabelece como princípio nas relações internacionais da República Federativa do Brasil a "cooperação entre os povos para o progresso da humanidade”.

O Princípio da cooperação se desdobra em outros dois princípios de finalidade parecida: Princípio da solidariedade e da não indiferença.

O Princípio da solidariedade traz a ideia de que os estados não são capazes de resolver seus problemas sozinhos, de forma isolada, de forma que uma ação conjunta é mais eficaz para solucionar os problemas ambientais. Já pelo Princípio da Não Indiferença, propugna-se uma sociedade mais igualitária e menos 
excludente. Defende a ideia de que os países menos favorecidos não podem ser desguarnecidos, tratando a temática da questão ambiental como algo que foge à individualidade de cada Estado.

A partir do assentamento de que a problemática ambiental transcende as fronteiras territoriais de cada Estado, constituindo-se um problema comum a todos, surge a questão polêmica acerca da autonomia dos Estados, da sua soberania, capaz de definir seus próprios rumos. A soberania seria absoluta? Ou o princípio da soberania poderia ser mitigado, frente à ideia de que o meio ambiente ecologicamente equilibrado, enquanto um direito humano está acima dos interesses privados de um Estado? É nesse contexto que surge o conflito entre o princípio da Não Intervenção e o princípio da Não Ingerência.

O princípio da não intervenção prega a soberania como garantia de autodeterminação do Estado. Vigora no Direito Internacional o Princípio da igualdade soberana entre os Estados, ao menos formalmente, não é lícito que algum venha a adentrar em questões internas de outro Estado.

A soberania assim é tratada na lição de Marcelo D. Varella (2010, p. 6)

O princípio da igualdade soberana pressupõe que todos os Estados são iguais perante o direito. Trata-se de um princípio derivado da idéia de comunidade internacional, que foi inspirada na comunidade de indivíduos, onde todos são iguais perante a lei. 0 princípio legitima o respeito entre os Estados, seja qual for seu porte, cultura, número de habitantes ou regime de governo. Não se trata de um atributo positivo, como um conjunto de poder de determinado Estado, mas um atributo negativo, que significa que os demais sujeitos de direito internacional não podem intervir sobre ele. 0 estado pode governar-se de acordo com seus próprios interesses.

Pelo princípio da não ingerência, por sua vez, a Organização das Nações Unidas somente poderá in- tervir em questões de interesse soberano dos Estados quando estes transcendem as fronteiras do Estado e, portanto, colocarem em risco toda a sociedade ambiental.

Não obstante a soberania de o Estado utilizar, livremente, os recursos naturais (Princípio $n^{0} 2$ da Convenção do Rio), a mesma não pode ser aplicada indistintamente, porque deve ser presente a razoabilidade, assim Paulo Affonso Leme Machado (2010, p. 1106):

Desse princípio da Declaração de Estocolmo decorre claramente que os Estados têm uma liberdade relativa ou uma liberdade controlada para a exploração de seus recursos naturais. Nesse sentido, entende-se que a soberania cria para os Estados obrigações que são corolário de seus próprios direitos.

Quando se trata de Direitos Humanos, a Comunidade Internacional tem de obrigatoriamente intervir na sua defesa.

A Declaração de Estocolmo representa um importante marco na concretização do direito ao meio ambiente ecologicamente equilibrado como algo universal, supra-estatal, convocando os agentes a uma participação comunitária na defesa dos interesses existentes.

Assim, assevera Varella (2010, p. 6):

O princípio do respeito aos direitos humanos sig nifica que todos os estados devem buscar a proteção dos direitos humanos, hoje considerado um valor comum a todos os sistemas de direito. Rep resenta ao mesmo tempo um objetivo comum e um pressuposto do direito internacional para o reconhecimento do próprio Estado. Existe uma parte dos teóricos de direito internacional que defende que o princípio da proteção internacional da pessoa humana é superior aos demais princípios inerentes à proteção do estado. Essa corrente fundamenta os atos da ONU sobre o direito de ingerência. Em casos extremos, a hierarquia a favor da proteção dos direitos humanos pode significar a desconsideração do princípio da soberania e da não-ingerência nos assuntos internos, como se identifica na expansão do direito internacional humanitário a 
partir dos anos noventa. Nesta lógica, admiti-se que a ONU não apenas pode, mas deve enviar tropas a um estado e, se necessário for, retirar determinado governo do poder para evitar graves violações aos direitos humanos.

\section{A SUPREMACIA DOS TRATADOS INTERNACIO- NAIS - GARANTIA CONSTITUCIONAL ASSEGU- RADA NA CR/88}

Várias considerações foram apontadas até o presente momento e uma delas que merece maior destaque neste momento, qual seja, é da conceituação das normas internacionais de direito ambiental, como Tratados Internacional de Direito Humanos.

Em breve apanhado, ficou mais do que comprovado que o meio ambiente equilibrado é de extrema importância para que o ser humano tenha uma vida com qualidade e com dignidade.

Neste ponto, a normas ambientais são norma de direitos humanos.

Desta feita, importante destacar a importância desta conclusão para demonstrar o crescimento que o Direito Ambiental obteve com a Emenda Constitucional 45 de 2004.

A Emenda Constitucional 45 de 2004 incluiu no art. $5^{\circ}$ da Constituição Federal o $\S 3^{\circ}$, que de maneira brilhante trouxe a possibilidade dos Tratados Internacionais de Direitos Humanos serem equiparados a Emenda Constitucional.

Art. $5^{\circ}$ Todos são iguais perante a lei, sem distinção de qualquer natureza, garantindo-se aos brasileiros e aos estrangeiros residentes no País a inviolabilidade do direito à vida, à liberdade, à igualdade, à segurança e à propriedade, nos termos seguintes:
$\S 3^{\circ}$ Os tratados e convenções internacionais sobre direitos humanos que forem aprovados, em cada Casa do Congresso Nacional, em dois turnos, por três quintos dos votos dos respectivos membros, serão equivalentes às emendas constitucionais. (Incluído pela Emenda Constitucional $n^{\circ} 45$, de 2004) (Atos aprovados na forma deste parágrafo).

Vejam que o Poder Constituinte derivado, diante da relevância dos Direitos Humanos, traz mais uma possibilidade de Emenda Constitucional.

Tal inovação serve para que com estas possibilidades os Tratados Internacionais Ambientais, por serem considerados como de Direitos Humanos, faça com que o Governo e a sociedade busquem, de maneira efetiva, a preservação e a atitude de sempre buscar o meio ambiente sadio, sustentável e equilibrado.

Lado outro, de grande valia foi a decisão recente do Supremo Tribunal Federal, mais precisamente no julgamento do HC 90751 e do RE 466343, em que o Ministro Gilmar Mendes, traz a baila a supremacia dos Tratados Internacionais de Direitos Humanos que não forem aprovados com quórum de Emenda Constitucional de serem considerados Infraconstitucional, porém com status supralegal:

EMENTA: PRISÃO CIVIL. Depósito. Depositário infiel. Alienação fiduciária. Decretação da medida coercitiva. Inadmissibilidade absoluta. Insubsistência 
da previsão constitucional e das normas subalternas. Interpretação do art. $5^{\circ}$, inc. LXVII e $\S \S 1^{\circ}, 2^{\circ}$ e $3^{\circ}$, da $\mathrm{CF}$, à luz do art. $7^{\circ}, \S 7$, da Convenção Americana de Direitos Humanos (Pacto de San José da Costa Rica). Recurso improvido. Julgamento conjunto do RE $\mathrm{n}^{\circ}$ 349.703 e dos HCs no 87.585 e no 92.566 . É ilícita a prisão civil de depositário infiel, qualquer que seja a modalidade do depósito.

(RE 466343, Relator(a): Min. CEZAR PELUSO, Tribunal Pleno, julgado em 03/12/2008, DJe-104 DIVULG 04-06-2009 PUBLIC 05-06-2009 EMENT VOL-0236306 PP-01106 RTJ VOL-00210-02 PP-00745 RDECTRAB v. 17 , n. 186,2010 , p. $29-165$ )

Importante destacar parte do voto do Ministro Gilmar Mendes, vejamos:

“[...] Em termo práticos, trata-se de uma declaração eloquente de que os tratados já ratificado pelo Brasil, anteriormente à mudança constitucional, e não submetidos ao processo legislativo especial de aprovação no Congresso Nacional, não podem ser comparados às normas constitucionais.

Não se pode negar, por outro lado, que a reforma também acabou por ressaltar o caráter especial dos tratados de direitos humanos em relação aos demais tratados de reciprocidade entre os Estados pactuantes, conferindo-lhes lugar privilegiado no ordenamento jurídico."

No trecho destacado fica clara a importância dada aos Tratados Internacionais de Direitos Humanos inserido pela emenda 45 de 2004, que levam a ruptura do entendimento que o Supremo Tribunal Federal vinha mantendo de aderir a legalidade ordinária dos tratados e convenções internacionais, vejamos:

[...] Em outros termos, solucionando a questão para o futuro - em que os tratados de direitos humanos, para ingressarem no ordenamento jurídico na qualidade de emendas constitucionais, terão que ser aprovados em quórum especial nas duas casas do Congresso Nacional, a mudança constitucional ao menos acena para a insuficiência da tese da legalidade ordinária dos tratados e convenções internacionais já ratificados pelo Brasil, a qual tem sido preconizada pela jurisprudência do Supremo Tribunal Federal

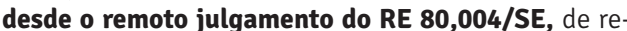

Latoria do Ministro Xavier de Albuquerque (julgado em $1^{\circ} .6,1977$; DJ 29,12,1977) e encontra respaldo em um largo repertório de casos julgados após o advento da Constituição de 1988[...].

Levando em consideração o já citado princípio da Cooperação, continua o voto da seguinte forma: “[...] É preciso pondera, no entanto, se, no contexto atual, em que se pode observar a abertura cada vez maior do Estado constitucional a ordens jurídicas supranacionais de proteção de direitos humanos, [...]"

Diante das ponderações articuladas pelo Ministro, o mesmo conclui pela necessidade de se dar mais efetividade à proteção dos direitos humanos nos planos interno e internacional, de maneira a mudar o entendimento da corte especial quanto ao papel dos tratados internacionais de direitos na ordem jurídica nacional.

A realidade da emergente postura jurisdicional em âmbitos supranacionais, voltada primordialmente à proteção do ser humano, necessita de cuidados especiais no que diz respeito à proteção dos direitos humanos, desta maneira a internalização no ordenamento jurídico, por meio do procedimento de ratificação Constitucional, tem o condão de paralisar a eficácia jurídica de todas e qualquer disciplina normativa infraconstitucional com ela conflitante. “[...] Tendo em vista o caráter supralegal desses diplomas normativos internacional, a legislação infraconstitucional posterior que com eles seja conflitante também tem sua eficácia paralisada. [...]".

Das considerações argumentativas demonstra a guinada no entendimento da Corte Suprema quanto à força dos Tratados Internacionais de Direito Humanos e uma nova visão para a aplicação de todas as normas ambientais internacionais de maneira a colidirem com as normas ambientais internas.

Diante da recepção dos Tratados Internacionais de Direitos Humanos, como supralegais necessários se 
faz que haja maior cautelar ao evocar e aplicar normas ambientais nacionais. As Normais Internacionais Ambientais passam a ter grande importância tendo, conforme já mencionado, força para paralisar a eficácia de normas que a contrarie.

\section{CONCLUSÃO}

A Declaração de Estocolmo representa um importante marco na concretização do direito ao meio ambiente ecologicamente equilibrado, como algo universal, supra-estatal, convocando os agentes à uma participação comunitária na defesa dos interesses existentes.

A partir da Declaração, a categoria "meio ambiente" passou a ser compreendida também como conjunto de recursos naturais e suas relações com o homem, dando início à compreensão do meio ambiente enquanto um direito humano.

Destaca-se que a proteção do meio ambiente deve ser integral e ampla, uma que se trata de bem coletivo, de interesse difuso, pertencente a todos os indivíduos

O bem ambiental se apresenta como um patrimônio de todos, universal, o que enseja uma cooperação entre todos os Estados para a sua preservação
Infere-se, assim, que o princípio da Soberania dos Estados não é algo absoluto, o meio ambiente enquanto direito humano permite a interferência da comunidade internacional frente a ocorrência de lesões.

Além do mais, a Emenda Constitucional 45 de 2004 trouxe inovações e alterações na jurisprudência da Suprema Corte, com que faz a possibilidade dos Tratados Internacionais de Direito Ambiental sejam equivalentes a emenda constitucional, se aprovado com quórum especial, ou por serem considerados como supralegais, ou seja, infraconstitucional e supralegal.

Deste modo, a nova sistemática é de extrema relevância para que os elaboradores, aplicadores e estudiosos do Direito Ambiental interno passem por reexame e sejam confrontados como todos os Tratados Internacionais de Direito Ambiental.

\section{REFEREENCAS}

ACCIOLY, Hildebrando. Manual de Direito Público, 17. ed. São Paulo: Saraiva, 2009.

BONAVIDES, Paulo. Curso de Direito Constitucional. 21. ed. São Paulo: Malheiros editores, 2007.

BRASIL. Constituição (1988). Constituição da República Federativa do Brasil. 28. ed. São Paulo: Atlas, 2007.

BULOS, Uadi Lammêgo. Constituição Federal Anotada, 3. ed. São Paulo: Saraiva, 2001. 
CANOTINHO, José Joaquim Gomes, LEITE, José Rubens Morato, (Org). Direito Constitucional brasileiro. 4. ed. São Paulo: Saraiva, 2011.

DERANI, Cristiane. Direito Ambiental econômico, 3. ed. São Paulo: Saraiva, 2008.

GOMES, Fabio Luiz. Direito Internacional. São Paulo: Saraiva, 2010,

MACHADO, Paulo Affonso Leme. Direito Ambiental Brasileiro. 18. ed. São Paulo: Malheiros, 2010.

MAZZUOLI, Valerio de Oliveira. Curso de Direito Internacional Público. 4. ed. São Paulo: Revista dos Tribunais, 2011.

MILARÉ, Edis. Direito do Ambiente. 6. ed. São Paulo: Revista dos Tribunais, 2009.

MORAES, Alexandre de. Direito Constitucional. 22. ed. São Paulo: Atlas, 2007.

VARELLA. Marcelo D. Direito internacional Público. 2. ed. São Paulo: Saraiva, 2010. 